\title{
Baroclinic Modes over Rough Bathymetry and the Surface Deformation Radius
}

\author{
J. H. LACASCE (1) \\ Department of Geosciences, University of Oslo, Oslo, Norway \\ SJOERD GROESKAMP \\ Royal Netherlands Institute for Sea Research, Texel, Netherlands
}

(Manuscript received 9 March 2020, in final form 28 July 2020)

\begin{abstract}
The deformation radius is widely used as an indication of the eddy length scale at different latitudes. The radius is usually calculated assuming a flat ocean bottom. However, bathymetry alters the baroclinic modes and hence their deformation radii. In a linear quasigeostrophic two-layer model with realistic parameters, the deep flow for a 100-km wave approaches zero with a bottom ridge roughly $10 \mathrm{~m}$ high, leaving a baroclinic mode that is mostly surface trapped. This is in line with published current meter studies showing a primary EOF that is surface intensified and has nearly zero flow at the bottom. The deformation radius associated with this "surface mode" is significantly larger than that of the flat bottom baroclinic mode. Using World Ocean Atlas data, the surface radius is found to be $20 \%-50 \%$ larger over much of the globe, and $100 \%$ larger in some regions. This in turn alters the long Rossby wave speed, which is shown to be $1.5-2$ times faster than over a flat bottom. In addition, the larger deformation radius is easier to resolve in ocean models.
\end{abstract}

KEYWORDS: Baroclinic flows; Ocean dynamics; Rossby waves

\section{Introduction}

Time-dependent eddies are ubiquitous in all ocean basins. They are generated by unstable boundary currents, by wind and buoyancy forcing, and are frequently observed to propagate westward (Chelton and Schlax 1996; Osychny and Cornillon 2004; Chelton et al. 2007, 2011; Klocker and Marshall 2014; Moreton et al. 2020). They have a privileged role in the ocean, transporting heat and other properties, and mediating oceanic adjustment to climatic changes in forcing (Anderson and Gill 1975; McCreary 1983; Huang et al. 2000; Dong and Sutton 2002). As such, resolving eddies is an important goal in ocean and climate modeling (Kirtman et al. 2012; Hallberg 2013).

Eddies have horizontal scales which vary strongly with latitude, being larger at low latitudes and smaller at high. Their scale is comparable to the first Rossby deformation radius, the eigenvalue associated with the first baroclinic mode (Stammer 1997; Chelton et al. 2011; Ajayi et al. 2020). Baroclinic modes, calculated with potential density from observations, are widely used in oceanography (Gill 1982; Wunsch 2015). Crucially, they are usually calculated by neglecting bottom topography, i.e., assuming the ocean bottom is flat.

There is mounting evidence, however, that bathymetry affects time-dependent motion throughout the water column. The first empirical orthogonal function (EOF) calculated with current meter data exhibits a characteristic shape in many extratropical regions, decaying from a maximum near the surface to near zero at the bottom (Wunsch 1997; de La Lama et al. 2016). The first EOF often captures $50 \%-90 \%$ of the variance, so this is a significant component of the motion. In contrast to this structure, the first baroclinic mode with a flat bottom changes sign at middepth and has opposed flow at the

Corresponding author: J. H. LaCasce, j.h.lacasce@geo.uio.no bottom. It has been argued that the EOF could be explained as a combination of the first baroclinic mode and the depthindependent barotropic mode, such that the bottom flow was canceled (Wunsch 1997; Tailleux and McWilliams 2001). But the EOF closely resembles the first baroclinic mode obtained over a rough bottom, i.e., assuming zero horizontal flow at the bottom (Aoki et al. 2009; Hunt et al. 2012; Wortham and Wunsch 2014; de La Lama et al. 2016).

Such modes ("surface modes" hereafter) occur over sufficiently large bottom slopes. For a $100-\mathrm{km}$ wave with realistic stratification, a linear slope of $10^{-3}$ is sufficient to reduce bottom velocities to near zero (LaCasce 2017). Simultaneously, the barotropic mode, present with a flat bottom, shifts to a bottomintensified topographic wave (Rhines 1970; Charney and Flierl 1981). Smaller waves are more sensitive to bottom slope and larger waves are less so, although in all cases the bottom velocity is very small with slopes greater than $10^{-2}$. Bottom slopes exceed $10^{-2}$ over midocean ridges and the continental slopes, but weaker slopes are found over the abyssal plains (e.g., Fig. 2 of LaCasce 2017). Nevertheless, the primary EOFs from current meter data resemble the first surface mode nearly everywhere (de La Lama et al. 2016). So what is reducing the bottom velocities?

One possibility is bottom roughness. A sinusoidal ridge with a wavelength of $1 \mathrm{~km}$ and a height of $10 \mathrm{~m}$ has a slope of order $10^{-2}$. As such, even weak bathymetry could be a potent means of suppressing deep flow. The effect of roughness on largescale waves was addressed previously, using two-layer models (Samelson 1992; Reznik and Tsybaneva 1999; Tailleux and McWilliams 2000) and continuous stratification (Bobrovich and Reznik 1999; Vanneste 2003). These studies indeed suggest a shift from flat bottom modes to surface modes and bottomintensified topographic waves over sufficiently high bumps.

The change in baroclinic modes has several potential consequences. The deformation radius of the first surface mode 
differs from that of the flat bottom mode. This in turn affects the long Rossby wave speed, which varies as the square of the deformation radius. Eddy propagation speeds are routinely compared to the long wave speed, but to the flat bottom value (e.g., Chelton and Schlax 1996; Chelton et al. 2011; Klocker and Marshall 2014; Moreton et al. 2020). However, imposing no flow at the bottom increases the phase speed (Tailleux and McWilliams 2001; Aoki et al. 2009; Hunt et al. 2012). The deformation radius is also a standard scale used for judging model resolution. Models fail to resolve eddies where the deformation radius is small, typically at high latitudes, and in such regions eddy mixing has to be parameterized (e.g., Gent and McWilliams 1990; Griffies 1998; McDougall and McIntosh 2001; Bachman and Fox-Kemper 2013).

Hereafter, we reexamine two-layer Rossby waves over a corrugated bottom, focusing on the topographic heights required to suppress the deep flow of the first baroclinic mode. As suggested above, bumps roughly $10 \mathrm{~m}$ high on scales of kilometers are sufficient to reduce the bottom velocities nearly to zero. Then we calculate the deformation radius associated with the first surface mode, using World Ocean Atlas data. After, we compare the long Rossby wave speed over rough and flat bathymetry and examine the effect on model resolution.

\section{Rossby waves over 10 bathymetry}

\section{a. Equations}

For the two-layer calculations, we employ a linear quasigeostrophic (QG) model. The system is essentially that studied by Samelson (1992), Reznik and Tsybaneva (1999), and Vanneste (2001); the present focus is on the dimensional roughness height required to alter the baroclinic mode. The nondimensional equations, with zero mean flow and no bottom friction, are (e.g., Pedlosky 1987)

$$
\begin{aligned}
\frac{\partial}{\partial t} q_{1}+\frac{\partial}{\partial x} \psi_{1} & =0 \\
\frac{\partial}{\partial t} q_{2}+\left(1+\eta \frac{\partial}{\partial y} h\right) \frac{\partial}{\partial x} \psi_{2} & =0
\end{aligned}
$$

where

$$
q_{j} \equiv \nabla^{2} \psi_{j}+F_{j}\left(\psi_{3-j}-\psi_{j}\right)
$$

are the layer potential vorticities, $F_{j}=f_{0}^{2} L^{2} /\left(g^{\prime} H_{j}\right)=L^{2} / L_{d j}^{2}$ are the Burger numbers in each layer, and $L$ is the wave scale. A wave time scale, $T=(\beta L)^{-1}$, is assumed, and

$$
\eta=\frac{f_{0} h_{0}}{\beta L H_{2}}
$$

is the nondimensional roughness height. ${ }^{1}$

\footnotetext{
${ }^{1}$ Samelson (1992) obtains a different nondimensional parameter by using the advective time scale, i.e., $T=L / U$. Reznik and Tsybaneva (1999) assumed the time scale much less than $f_{0}^{-1}$, as with an advective time scale and a small Rossby number. Given the present emphasis on the surface mode, the wave time scale is appropriate.
}

The bathymetry $h$ is assumed to be one dimensional and varying only in $y$ (Samelson 1992; Reznik and Tsybaneva 1999; Bobrovich and Reznik 1999; Tailleux and McWilliams 2000; Vanneste 2001). Different orientations are possible, by rotating the $\beta$ term (e.g., Reznik and Tsybaneva 1999; Vanneste 2003 ), but the $y$ variation is retained here for simplicity. We assume further that

$$
h=\cos \left(l_{t} \pi y\right)
$$

Additional harmonics (or even random bathymetry) are easily incorporated, but this choice allows identifying a single topographic length scale.

We seek solutions which are wavelike in $x$ and $t$, i.e.,

$$
\psi_{j}=\hat{\psi}_{j}(y) e^{i k(x-c t)}
$$

This yields a generalized eigenvalue problem:

$$
\begin{array}{r}
\hat{\psi}_{1}=c\left(\frac{\partial^{2}}{\partial y^{2}}-k^{2}-F_{1}\right) \hat{\psi}_{1}+c F_{1} \hat{\psi}_{2}, \\
\left(1+\eta \frac{\partial}{\partial y} h\right) \hat{\psi}_{2}=c F_{2} \hat{\psi}_{1}+c\left(\frac{\partial^{2}}{\partial y^{2}}-k^{2}-F_{2}\right) \hat{\psi}_{2} .
\end{array}
$$

Solutions were obtained numerically using a Chebyshev grid in $y$ and differentiation as specified by Trefethen (2001). The wave domain is a channel, with $\psi_{1}=\psi_{2}=0$ at the channel walls (at $y= \pm 1$ ), and the solutions were well resolved with 200 grid points in the meridional direction; the results in most cases were the same with 100 grid points and not different with 400 grid points. The channel is open in the zonal direction, but fractional values of the zonal wavenumber are used so that the solutions are not necessarily zonally periodic.

We will focus on the first baroclinic mode phase speed. We compare the calculated value with the baroclinic phase speed obtained over a flat bottom and with that for the mode confined to the upper layer. The flat bottom speed, derived from a plane wave solution to (1) and (2), is given by (Pedlosky 1987)

$$
c_{f 1}=-\frac{1}{K^{2}+F_{1}+F_{2}},
$$

where $K^{2}=k^{2}+l_{n}^{2} \pi^{2}$ is the squared horizontal wavenumber, if $l_{n}$ is the cross-channel wavenumber. For the gravest crosschannel mode, $l_{1}=1 / 2$ so that

$$
\psi_{j}=\hat{\psi}_{j} e^{i k(x-c t)} \cos \left(\frac{\pi y}{2}\right)
$$

With no flow in the lower layer, the plane wave solution to Eq. (1) has a phase speed

$$
c_{s 1}=-\frac{1}{K^{2}+F_{1}} .
$$

This is faster than the flat bottom speed. In the long wave limit, when $K^{2} \ll F_{1}$, the phase speed is greater by a factor of $\left(F_{1}+\right.$ $\left.F_{2}\right) / F_{1}=\left(H_{1}+H_{2}\right) / H_{2}$ (Samelson 1992; Reznik and Tsybaneva 1999; Tailleux and McWilliams 2000). 


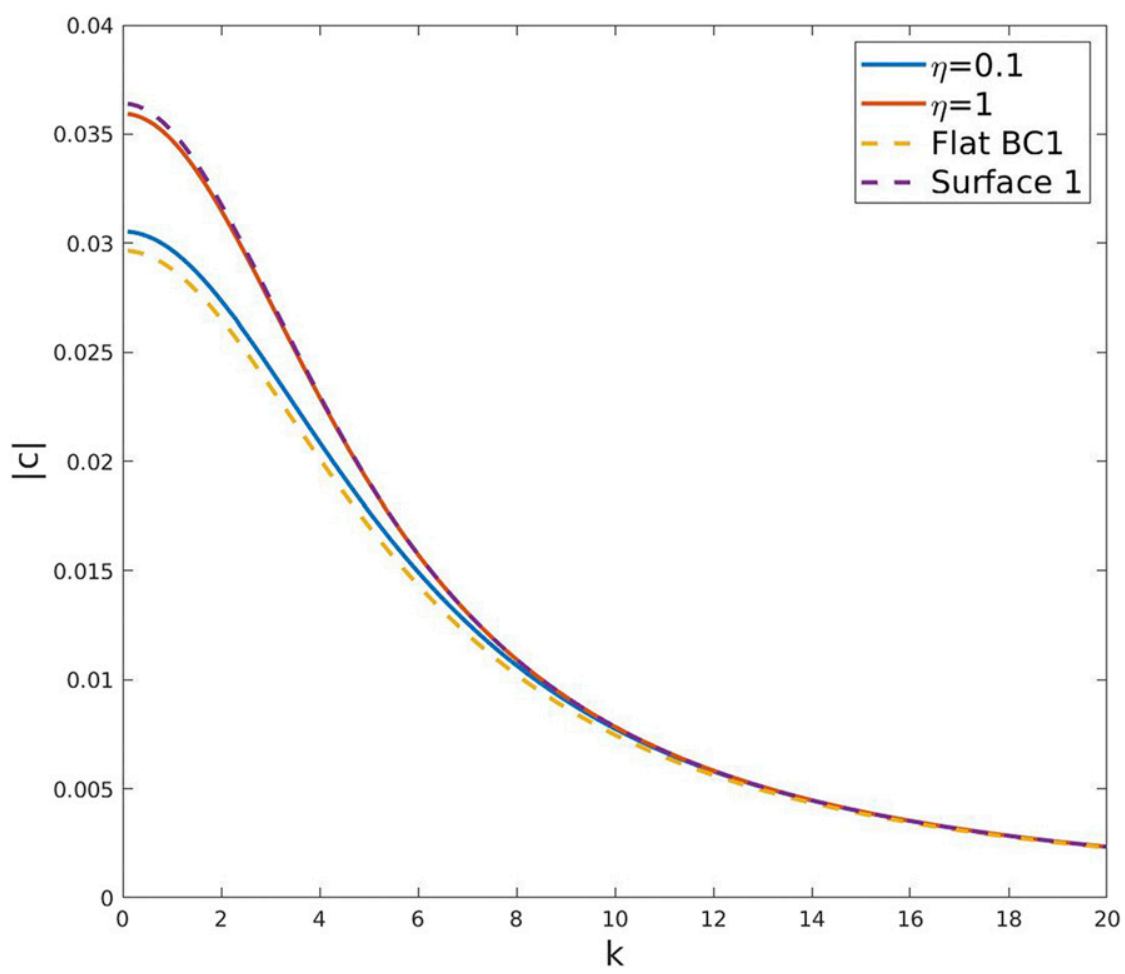

FIG. 1. The absolute value of the phase speed in the two-layer model vs the zonal wavenumber $k$ with two values of the ridge height $\eta$. The deformation radius and the bump wavelength are $1 / 5$ and $1 / 10$ the wave scale, respectively. The dashed curves show the phase speeds for the first flat bottom baroclinic and surface modes.

\section{b. Results}

When calculating the response, we fix the layer depth ratio $H_{1} / H_{2}=1 / 4$, as for a 5000-m-deep ocean with a thermocline depth of $1000 \mathrm{~m}$. The results are qualitatively insensitive to the choice, and similar results obtain with ratios from $1 / 2$ to $1 / 10$. We also focus on the gravest mode in the cross-channel direction.

The dispersion relations for a wave 5 times larger than the deformation radius $\left(F_{1}=25\right)$ and a topographic wavenumber of $l_{t}=10$ are shown in Fig. 1. The absolute value of the phase speed is plotted against the zonal wavenumber, with bottom heights of $\eta=0.1$ and $\eta=1$. The dispersion relations for the flat bottom and surface mode waves [Eqs. (7) and (9)] are shown for comparison.

With $\eta=0.1$, the solution lies between the flat bottom and surface mode dispersion relations. Thus the phase speed exceeds that over a flat bottom but is slower than for a surface mode. But with $\eta=1$, the solution is close to the surface mode relation. This suggests the baroclinic mode is nearly trapped in the upper layer.

The streamfunctions (Fig. 2) support this. Shown are the solutions with $k=1$ (yielding an approximately isotropic wave). With $\eta=0.1$, the deep flow resembles the negative of the surface flow, as expected for a flat bottom baroclinic mode. The ridges distort the deep flow, but the streamfunction amplitude is still $30 \%$ of that in the upper layer. With $\eta=1$ though, the bottom streamfunction is nearly 10 times weaker and shows the strong influence of the bathymetry, with the contours closing over each ridge. Note though that the bottom flow is not zero. Having a higher ridge reduces the amplitude, but the bottom flow is still present, though weak.

The dependence on bump height for three different size waves is shown in the left panel of Fig. 3. For this, we calculated the phase speed with $k=1$ and normalized by the phase speed of the corresponding surface mode wave. With all three meridional scales $\left(L=L_{d 1}, L=5 L_{d 1}, L=10 L_{d 1}\right)$, the phase speed asymptotes to the surface mode value roughly by $\eta=1$. Thus with this topographic height or larger, the baroclinic mode is mostly trapped in the upper layer.

The results are not strongly sensitive to the wavelength of the bumps. Consider the case with $L=5 L_{d 1}$ and $k=1$. Varying the topographic wavenumber $l_{t}$ yields the phase speeds shown in the right panel of Fig. 3. There is some variation (up to 5\%) for wavenumbers less than 5 , i.e., when the topographic wavelength is comparable to that of the wave; in such cases, strong, localized bottom flows can be seen. But such wavetopography coupling is absent for larger topographic wavenumbers, and the phase speeds converge to a constant value. Thus, for this scale wave, the same surface trapping occurs for ridge wavelengths deformation scale or smaller.

Interestingly, a similar result is found with the linear stability of a jet over corrugations (Benilov 2001; Vanneste 2003; LaCasce et al. 2019). As long as the ridge wavelength is an order of magnitude less than the jet width, the results are 

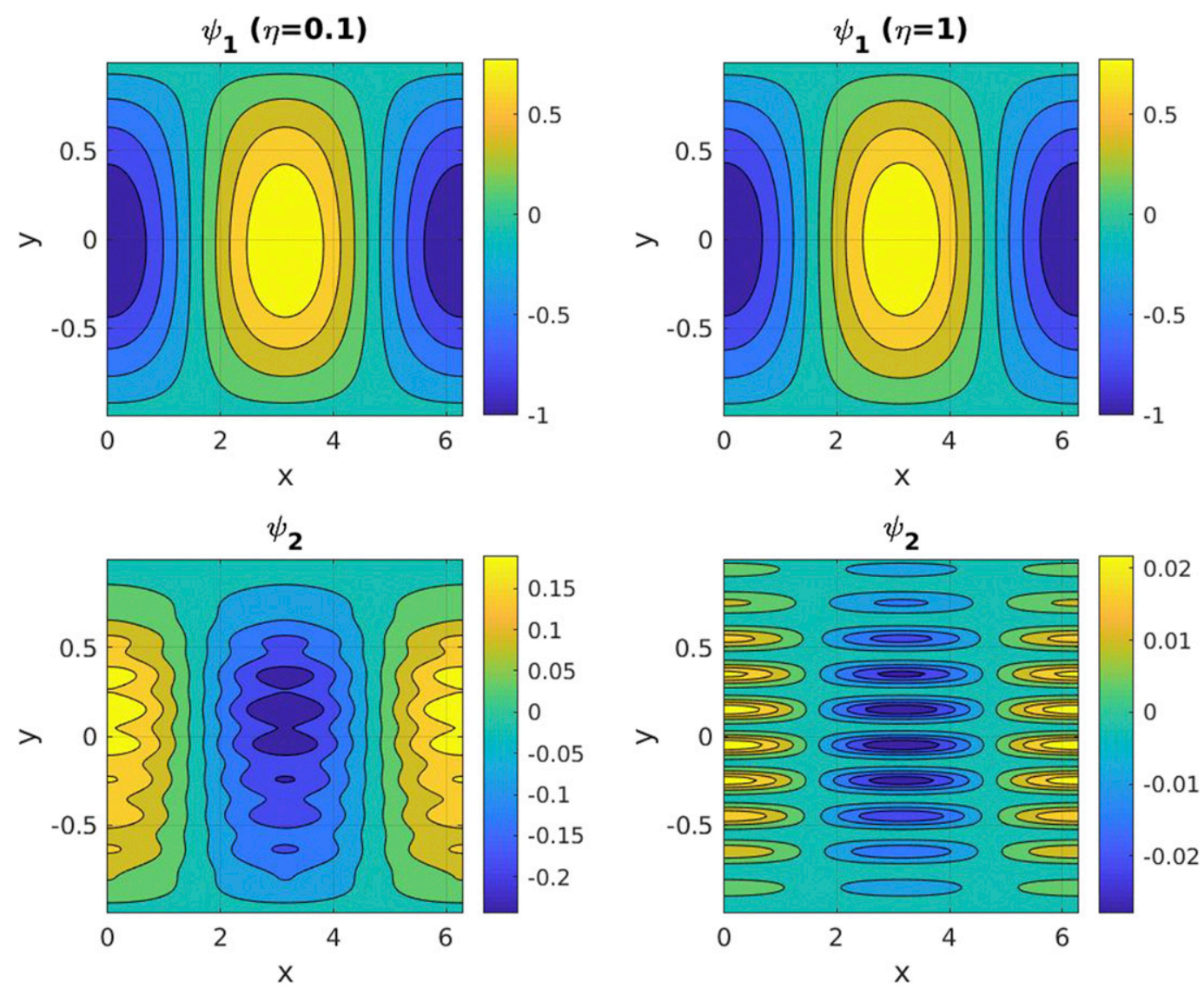

FIG. 2. The surface and bottom streamfunctions over a sinusoidal ridge with a wavenumber $l_{t}=10$ and heights (left) $\eta=0.1$ and (right) $\eta=1$.

insensitive to the former. Then the topographic amplitude is the primary factor determining the deep suppression.

\section{c. Ridge height}

Thus, having a ridge with an amplitude of $\eta=1$ suppresses the bottom flow. But how high is this? Inverting the expression for $\eta$ from (3), we have

$$
h_{0}=\frac{\beta \eta L H_{2}}{f_{0}} .
$$

Using approximate midlatitude values,

$$
H_{2} \approx 10^{3} \mathrm{~m}, \quad \beta \approx 10^{-11}(\mathrm{~m} \mathrm{~s})^{-1}, \quad f_{0}=10^{-4} \mathrm{~s}^{-1}
$$

yields $h_{0}=O|10| \mathrm{m}$ for a $100 \mathrm{~km}$ wave if $\eta=1$. A $100-\mathrm{m}$-high ridge is required for $1000-\mathrm{km}$ waves, but that required for a $10-\mathrm{km}$ wave is only about $1 \mathrm{~m}$. Bump heights of $10-50 \mathrm{~m}$ are routinely found on 10-km scales (Goff 2010; LaCasce et al. 2019).

The equivalent slopes for suppression, assuming a $10-\mathrm{km}$ ridge, are thus $10^{-3}$ for a $100-\mathrm{km}$ wave, $10^{-2}$ for a $1000-\mathrm{km}$ wave and $10^{-4}$ for a $10-\mathrm{km}$ wave. These values are comparable to those required with continuous stratification and a linear slope (LaCasce 2017).
Nevertheless, some caution is warranted as the two-layer model may have a stronger sensitivity to topography than a continuously stratified model, as also noted by Bobrovich and Reznik (1999). The topography with continuous stratification enters via the (linear) QG density equation at the bottom:

$$
\frac{\partial}{\partial t} \frac{\partial \psi}{\partial z}+\frac{N^{2}}{f_{0}} w=\frac{\partial}{\partial t} \frac{\partial \psi}{\partial z}+\frac{N^{2}}{f_{0}} \frac{\partial h}{\partial y} \frac{\partial \psi}{\partial x}=0 .
$$

Scaling this, again with a Rossby wave time scale, yields a nondimensional ridge height of

$$
\eta=\frac{h_{0} H N_{b}^{2}}{f_{0} \beta L^{3}},
$$

where $N_{b}$ is the buoyancy frequency at the bottom. Inverting the expression yields

$$
h_{0}=\frac{f_{0} \beta \eta L^{3}}{H N_{b}^{2}}=\frac{\beta \eta L H}{f_{0}}\left(\frac{L}{L_{b}}\right)^{2},
$$

where $L_{b}=N_{b} H / f_{0}$ is the deformation radius evaluated with the bottom stratification. The first term on the RHS of (13) is approximately the same as that in the two-layer estimate (3), but the term in parentheses will typically be larger than one. 

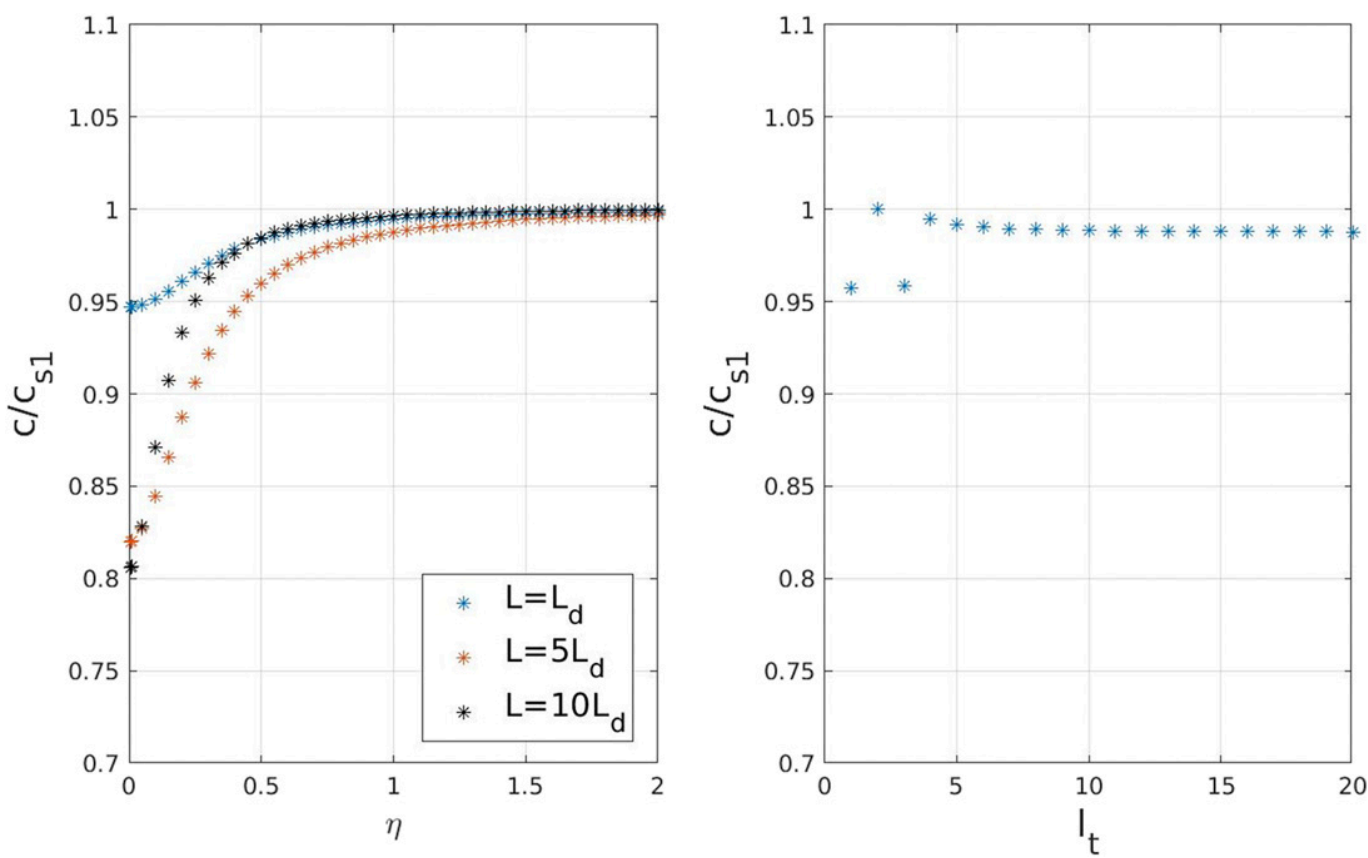

FIG. 3. (left) The phase speed vs the bump height with $k=1$ and three different wavelengths $(1,5$, and 10 times the deformation scale). The phase speeds are normalized by the surface wave value for each wave, $c_{s 1}=-1 /\left(K^{2}+\right.$ $\left.F_{1}\right)$. (right) The phase speed normalized by the surface mode speed vs the bump wavenumber $l_{t}$, with $k=1, \eta=1$, and $L=5 L_{d}$.

As such, the heights required to suppress the deep flow could indeed be larger with continuous stratification. This simple scaling argument may overestimate the required height, as it neglects the change in the vertical scale of $\phi(z)$ (LaCasce 2017). Nevertheless, the topographic influence may well be less with continuous stratification.

\section{The deformation radius}

Thus, the surface mode/topographic wave decomposition is probably applicable is most regions. Whether the reader is convinced by the theoretical arguments or not, the current meter results remain, indicating that a mode closely resembling the first surface mode accounts for $50 \%-90 \%$ of the variance in many extratropical locations (de La Lama et al. 2016). Significantly, the first surface mode has a larger deformation radius than the first flat bottom mode, and this has several implications, as follows.

\section{a. Methods}

We will examine the first surface mode from climatological potential density. If the buoyancy frequency $N$ is a function only of $z$, the linear QG potential vorticity equation is separable, yielding an equation for the vertical structure: (Gill 1982; Pedlosky 1987; Chelton et al. 1998; Wunsch 2015):

$$
\frac{d}{d z}\left(\frac{1}{N^{2}} \frac{d \phi}{d z}\right)+\frac{1}{c^{2}} \phi=0
$$

where $\phi(z)$ is the vertical structure function. The buoyancy frequency is defined such that

$$
N^{2}(z)=g\left(\alpha \frac{\partial \Theta}{\partial z}-\frac{\partial S_{\mathrm{A}}}{\partial z}\right) \approx-\frac{g}{\rho} \frac{\partial \rho_{1}}{\partial z},
$$

where $\Theta$ is the Conservative Temperature and $S_{\mathrm{A}}$ the Absolute Salinity (see below), $\rho_{1}$ is the locally referenced potential density and $\rho$ the density.

For the boundary conditions, a rigid upper surface is assumed at $z=0$, so that the vertical velocity and hence the vertical derivative of $\phi$ vanish. For the traditional baroclinic mode calculation, the same condition $(\partial \phi / \partial z=0)$ is applied at the bottom, at $z=-H$. The resulting Sturm-Liouville problem yields a discrete set of eigenfunctions $\phi(z)$ and eigenvalues, $c=$ $c_{n}$, the phase speeds of long, mode- $n$ gravity waves (Gill 1982). The gravest mode is the depth-invariant barotropic mode, while the higher (baroclinic) modes vary with depth.

The surface mode is found by instead setting $\phi=0$ at $z=-H$, so that there is no horizontal flow at the bottom (Aoki et al. 2009; Hunt et al. 2012; Wortham and Wunsch 2014; de La Lama et al. 2016). The preceding two-layer calculations suggest the bottom velocities may not actually be zero, but regardless the calculated phase speeds more closely agree with the surface mode. The resulting (continuous) modes are surface intensified and resemble the flat-bottom modes except that they have a node at the bottom. The surface modes constitute a complete basis and have sequentially decreasing phase speeds. The first surface mode decays monotonically from the surface to the bottom without changing sign and closely resembles the gravest EOF from the current meter observations (de La Lama et al. 2016).

The barotropic mode, which has a nonzero bottom velocity, is eliminated by the rough bottom boundary condition. 
As noted, bottom velocities are associated with topographic waves in the strong topographic limit. These represent the solution to Eq. (14) when the eigenvalue $c$ is imaginary (e.g., Rhines 1970; Charney and Flierl 1981).

With realistic stratification, Eq. (14) must be solved numerically. We do this using a shooting method with a fourthorder Runge-Kutta step, integrating down from the surface. ${ }^{2}$ The eigenvalue is adjusted using Newton's method until either of the two bottom conditions (flat or rough) is satisfied.

The buoyancy frequency is calculated from the Conservative Temperature and Absolute Salinity (McDougall 2003; McDougall et al. 2012) (http://www.teos-10.org/). The data are obtained from annual mean fields from the World Ocean Atlas 2018 gridded climatology (https://www.nodc.noaa.gov/OC5/woa18/). First, the WOA in situ temperature and practical salinity are used to calculate $\Theta$ and $S_{\mathrm{A}}$ using the GSW software toolbox (McDougall and Barker 2011), and are then interpolated to a 10 -m vertical grid resolution using interpolation software (Barker and McDougall 2020). The resulting data are made statically stable (Barker and McDougall 2017), with a minimum stability as specified by Jackett and McDougall (1997). The buoyancy frequency is then calculated using (15) and smoothed with a five-point running mean, to filter out small scale oscillations; the latter prevented numerical convergence in some extreme cases.

The first mode deformation radius is proportional to the first eigenvalue $c_{1}$ (the barotropic mode is the "zeroth" mode, with a phase speed $c_{0}$ ). In the extratropics, the deformation radius is given by

$$
L_{d}=\frac{c_{1}}{|f|},
$$

where $f$ is the Coriolis parameter at the chosen latitude. In the tropics, where $f$ is small, the equatorial deformation radius is used instead:

$$
L_{d}=\left(\frac{c_{1}}{2 \beta}\right)^{1 / 2}
$$

where $\beta=d f / d y$ is the latitudinal gradient of the Coriolis parameter. We employ an expression due to Hallberg (2013) to transfer smoothly between the two expressions, specifically

$$
L_{d}=\frac{c_{1}}{\sqrt{f^{2}+2 \beta c_{1}}} .
$$

Chelton et al. (1998) demonstrated that a WKB solution to the eigenvalue problem (valid under the assumption that buoyancy frequency varies more slowly with depth than the vertical structure function) yields fairly accurate values of the deformation radius. The WKB estimate, given by

\footnotetext{
${ }^{2}$ An alternate approach is to solve the discretized matrix problem (Chelton et al. 1998). Such a method, which also employs a rescaling to hasten convergence, is available at https://github.com/ NOAA-GFDL/MOM6/blob/dev/gfdl/src/diagnostics/MOM_wave_ speed.F90 (R. Hallberg 2020, personal communication).
}

$$
L_{d}=\frac{1}{\pi|f|} \int_{-H}^{0} N(z) d z,
$$

is well known and easily evaluated. This expression shows that the deformation radius is large where the depthintegrated stratification is large and where $f$ is small, i.e., at low latitudes.

We will also examine the WKB solution with zero horizontal flow at the bottom. The solution in this case is less straightforward, as the boundary conditions are mixed (Neumann at the surface and Dirichlet at the bottom). The solution moreover involves the vertical gradient of $N(z)$ near the surface and requires solving a transcendental equation (see the appendix). This makes it a somewhat less attractive option than with a flat bottom.

We will also compare the long (planetary) wave phase speeds obtained with the two bottom conditions. In QG, the (dimensional) long wave phase speed is given simply by

$$
c_{p}=-\beta L_{d}^{2}
$$

\section{b. Eigenfunctions and deformation radii}

Examples of the first baroclinic flat bottom and surface modes, obtained with stratification at $30^{\circ} \mathrm{S}, 160.5^{\circ} \mathrm{W}$, are plotted in Fig. 4. The flat bottom mode (left panel, green curve) is surface intensified, decreasing to half the surface amplitude by $1000 \mathrm{~m}$, and crosses zero near 1600-m depth. The mode has the opposite sign at the bottom, with an amplitude roughly $30 \%$ that at the surface. The WKB approximation (the black curve) has a similar shape, although it decays somewhat faster with depth, crossing zero near $1200 \mathrm{~m}$.

In contrast, the first surface mode (the blue curve in the right panel) is positive at all depths. It decays to half the surface amplitude by about $1200 \mathrm{~m}$ and decreases monotonically to zero below. The WKB approximation (orange curve), though noisier, exhibits the same behavior. In fact, the WKB estimate agrees more closely with the numerical solution than in the flat bottom case.

The deformation radii along the $160.5^{\circ} \mathrm{W}$ meridian are shown in Fig. 5. The flat bottom deformation radius (green curve) exhibits a strong dependence on latitude, decreasing from several hundred kilometers near the equator to less than $10 \mathrm{~km}$ at high latitudes. Consistent with Chelton et al. (1998), the WKB approximation (plotted in black) agrees well with the numerically derived values over most of the extratropics. This supports using Eq. (19) to estimate the flat bottom radius.

The first surface mode radius (blue curve) exhibits a similar dependence on latitude but is also consistently larger, both in the tropics and at higher latitudes. However, the surface WKB estimate (orange dotted curve) is generally too large. This is particularly noticeable at latitudes equatorward of about $40^{\circ}$.

Thus while the WKB solution yields a reasonable estimate of the flat bottom deformation radius, it produces less accurate modal structures. The opposite is true for the surface modes, as the WKB eigenvalues are consistently too large, but the vertical structure is reasonably well captured. 


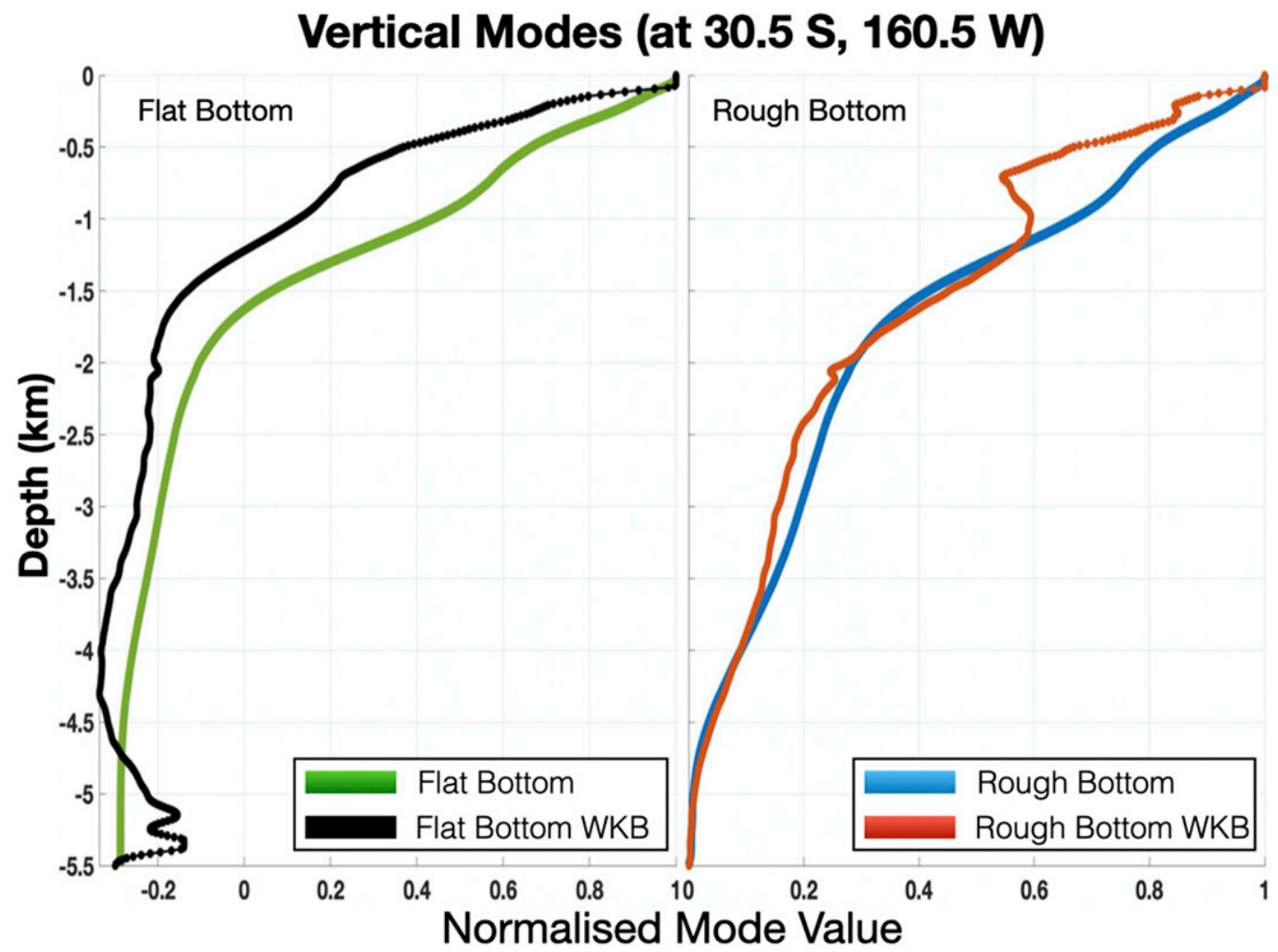

FIG. 4. Normalized vertical modes at $30^{\circ} \mathrm{S}, 160.5^{\circ} \mathrm{W}$. (left) The first flat bottom baroclinic mode (green curve) and the comparable WKB solution (black dotted curve), and (right) the first surface mode (blue curve) and associated WKB solution (orange dotted curve).

\section{c. Long wave phase speed}

The eigenvalue $c_{1}$ from (14), i.e., the first gravity mode phase speed assuming no flow at the bottom, is mapped in Fig. 6. This should be compared to Fig. 2 of Chelton et al. (1998), which maps the same quantity assuming a flat bottom. The two fields agree in the spatial variations, with larger phase speeds occurring in the western subtropical gyres and in deeper water. This is consistent with the WKB solution [Eq. (19)], which implies the gravity wave speed is proportional to the buoyancy frequency integrated over depth. But the speeds obtained with zero flow at the bottom are consistently larger.

This in turn impacts the long Rossby wave speed, which derives from $c_{1}$ as

$$
c_{p}=-\beta L_{d}^{2}=-\frac{\beta c_{1}^{2}}{f^{2}+2 \beta c_{1}} .
$$

At midlatitudes $c_{p}$ varies with $c_{1}^{2}$, so an increase in the latter greatly enhances the former. At low latitudes the dependence on $c_{1}$ is linear, so the enhancement is less.

The ratio of the surface mode long wave speed to the flat bottom one, zonally averaged over the Pacific, is shown in Fig. 7. The surface mode phase speed is indeed greater at all latitudes. The ratio is near 1.5 at the lower latitudes outside the tropics, and increases to 2 at higher latitudes.

The discrepancy is similar to that between the westward phase speed deduced from satellite observations and the flat bottom long wave speed (Chelton and Schlax 1996). This is indicated by the orange dots in the figure, extracted from Fig. $5 \mathrm{~b}$ of their paper. While there are differences between the two estimates, for instance near $40^{\circ} \mathrm{S}$, the increase over the flat bottom estimate is of a similar magnitude. Thus the change in bottom boundary condition is a plausible explanation for why the observed propagation speed is faster than expected from

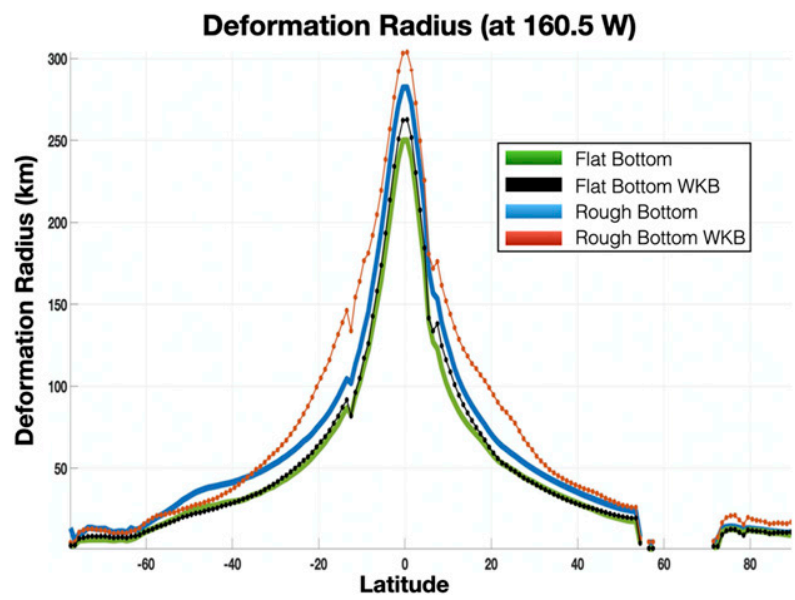

FIG. 5. The deformation radius at $160.5^{\circ} \mathrm{W}$ for the same four solutions as in Fig. 4, using the same color code. 


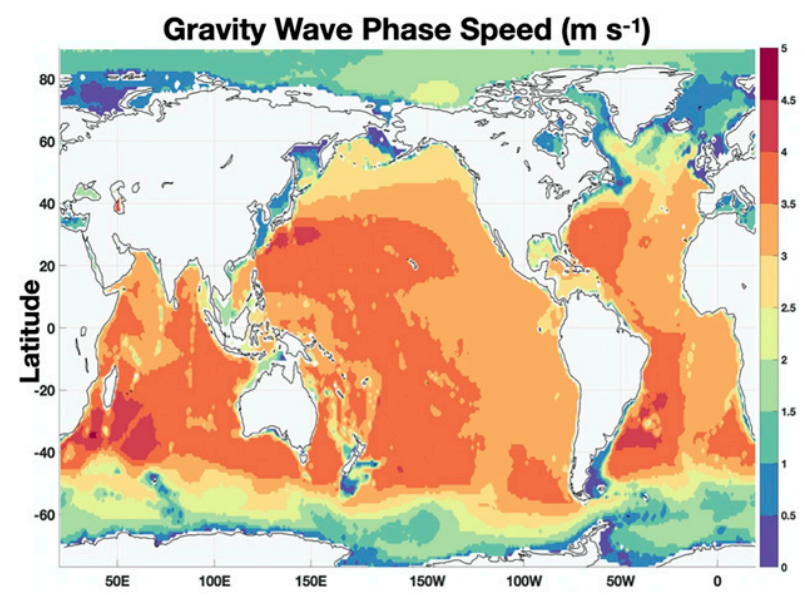

FIG. 6. The first gravity wave phase speed, obtained from the solution to Eq. (14) with zero flow at the bottom. The figure should be compared to Fig. 3 of Chelton et al. (1998), which shows the same quantity with a flat bottom.

standard Rossby wave theory. This was suggested previously by Tailleux and McWilliams (2001), Aoki et al. (2009), and Hunt et al. (2012), as discussed below.

\section{d. Mapping the deformation radius}

Using the phase speed and relations [(16) and (17)], we construct a map of the first surface radius (Fig. 8). The flat bottom deformation radius is not shown, but our method yields nearly identical results as those shown in Fig. 6 of Chelton et al. (1998). The surface radius decreases moving away from the tropics, with typical midlatitude values of $30-40 \mathrm{~km}$ and 10 $20 \mathrm{~km}$ at high latitudes. Over much of the Southern Ocean the radius is $20 \mathrm{~km}$. Undulations are seen the midocean ridges, particularly in the Atlantic and in the Southern Ocean, where the water depth is less (Chelton et al. 1998).

The relative increase in deformation radius when shifting from flat bottom to surface modes is mapped in Fig. 9, with the longitudinally averaged ratio of the surface to flat bottom radius in the insert on the right. The surface radius at midlatitudes is typically $25 \%$ larger than the flat bottom estimate. The difference is greater in the subpolar gyre regions (nearer 50\%) and is about twice as large in the Southern Ocean, particularly in the Weddell Gyre region. The differences are less dramatic in the Arctic, however, with increases on the order of $10 \%-20 \%$.

It is worth remembering that the observed flow is often more barotropic at high latitudes. Rather than reflecting the surface mode, this could be an indication of the topographic mode, which, for length scales exceeding the deformation radius, is nearly barotropic. The topographic mode moreover has different length scales, as determined by the bathymetry itself. Nevertheless, baroclinic eddies are observed at high latitudes, for example in the eastern Nordic Seas and in the Arctic. The surface mode radius is obviously more relevant for such structures.

\section{e. Model resolution}

The deformation radius is a standard measure for assessing the resolution of ocean models. The resolution requirements

\section{Ratio Rough over Flat bottom phase speed.}

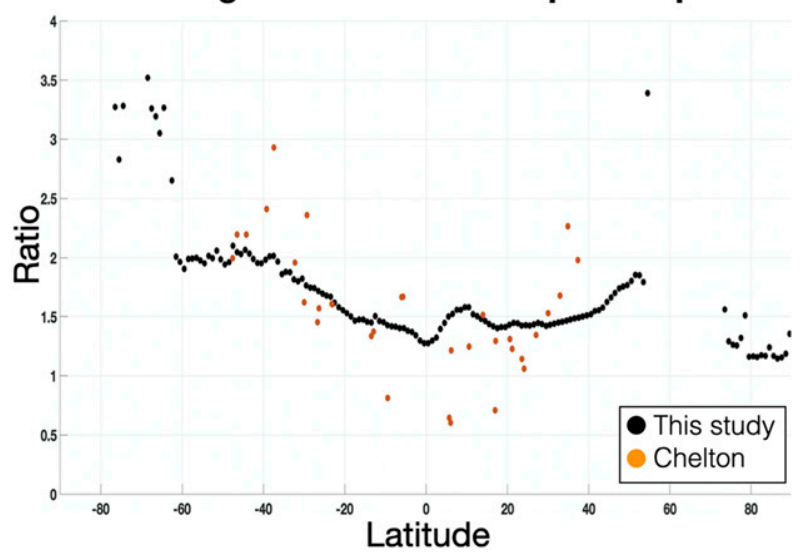

FIG. 7. The ratio of the surface mode and flat bottom baroclinic long Rossby wave speeds (black dots), and the ratio of satellitederived phase speeds in the Pacific to the flat bottom long wave speeds, obtained with data from Fig. 5b of Chelton and Schlax (1996) (orange dots).

are somewhat less stringent with the first surface radius than for the traditional deformation radius. We illustrate this by plotting the resolution required to capture the first surface radius with two grid points (the lower limit for a model to be considered "eddy resolving"), as done previously for the flat bottom radius by Hallberg (2013).

The result is shown in Fig. 10 . A $1^{\circ}$ model is sufficient to capture the surface radius at low latitudes, while $1 / 5^{\circ}$ resolution is required at midlatitudes and $1 / 25^{\circ}$ over much of the high latitudes.

Our map corresponding to the flat bottom deformation radius is not shown, but compares well to that of Hallberg (2013). The difference between the resolution required in the two cases, averaged zonally, is shown in the panel on the right in Fig. 10. As expected, the required grid spacing is larger with the surface mode. The difference is up to a fifth of a degree at low latitudes, falling to about $1 / 20^{\circ}$, or roughly $5 \mathrm{~km}$, at midlatitudes. The maximum differences are larger, but of the same order of magnitude.

While the changes are modest, the required resolution is less stringent. The $1 / 25^{\circ}$ resolution required at high latitudes is still well beyond the scope of modern climate models, but several global or large regional models currently have resolution exceeding this (e.g., Rocha et al. 2016; Chassignet and Xu 2017).

\section{Discussion}

A two-layer QG model with a submarine ridge indicates that surface modes-baroclinic modes with nearly zero horizontal velocity at the bottom-obtain when the topographic height exceeds roughly $10 \mathrm{~m}$. This is the case in many regions (Goff 2010; LaCasce et al. 2019). Deep flow suppression by roughness may thus explain why the primary EOF from current meter observations closely resembles the first surface mode in many locations (de La Lama et al. 2016).

There are several implications. The surface mode deformation radius is $20 \%-50 \%$ larger than over a flat bottom. 


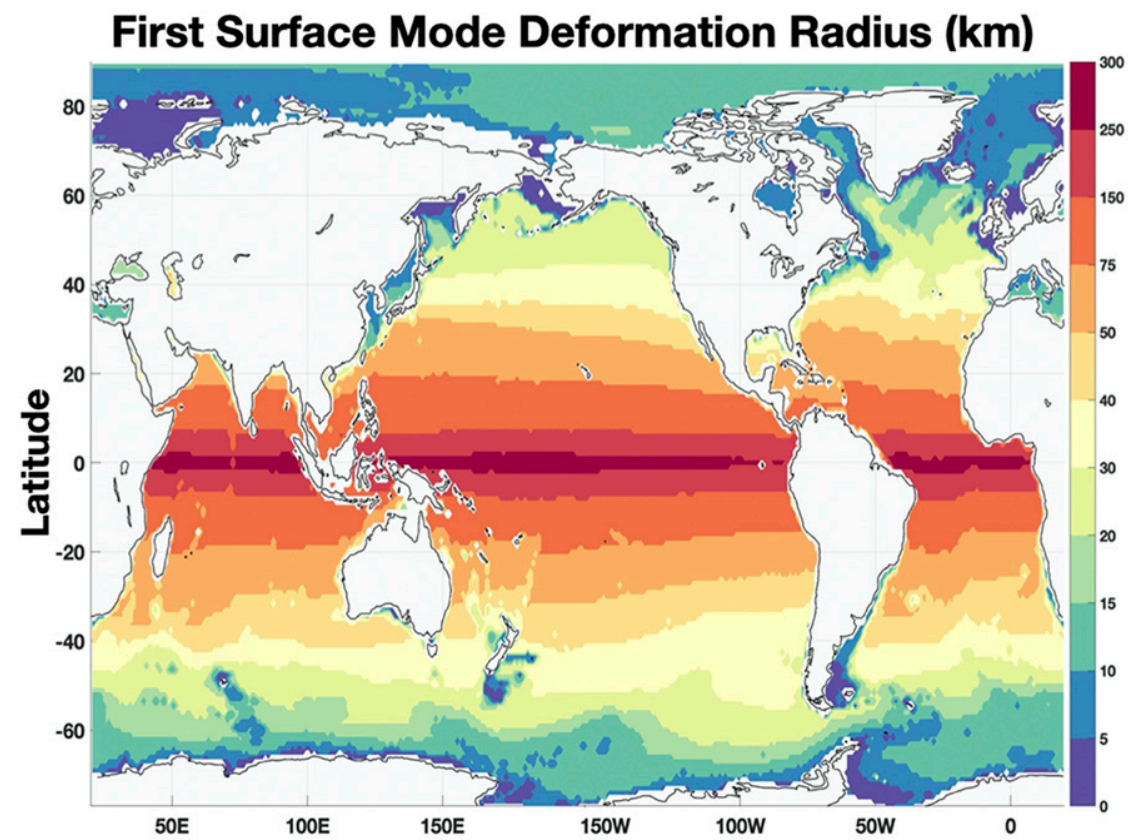

FIG. 8. The first surface mode deformation radius, obtained from the first eigenvalue from (14) and using expression (18).

Having a larger radius impacts eddy propagation speeds, as the long planetary wave phase speed varies with the square of the radius. Having a larger deformation radius also lessens the demands on ocean models, as larger eddies are easier to resolve.
It is known that eddy scales are correlated with the deformation radius (e.g., Stammer 1997; Chelton et al. 2011; Klocker and Marshall 2014). The present results suggest the observed scales should be compared to the first surface radius instead. The dominant eddy scale in the extratropics typically exceeds

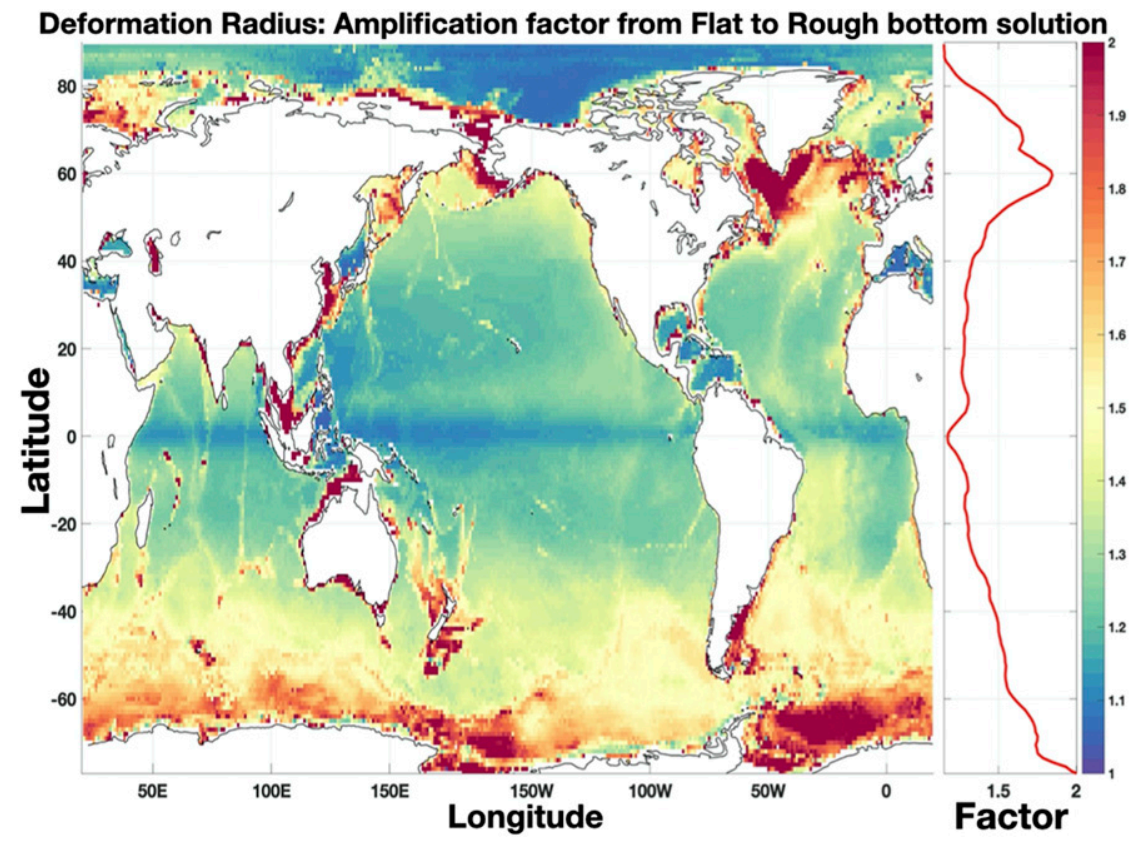

FIG. 9. The relative increase in deformation radius when using surface modes instead of flat bottom modes. The zonal mean is shown in the insert on the right. 


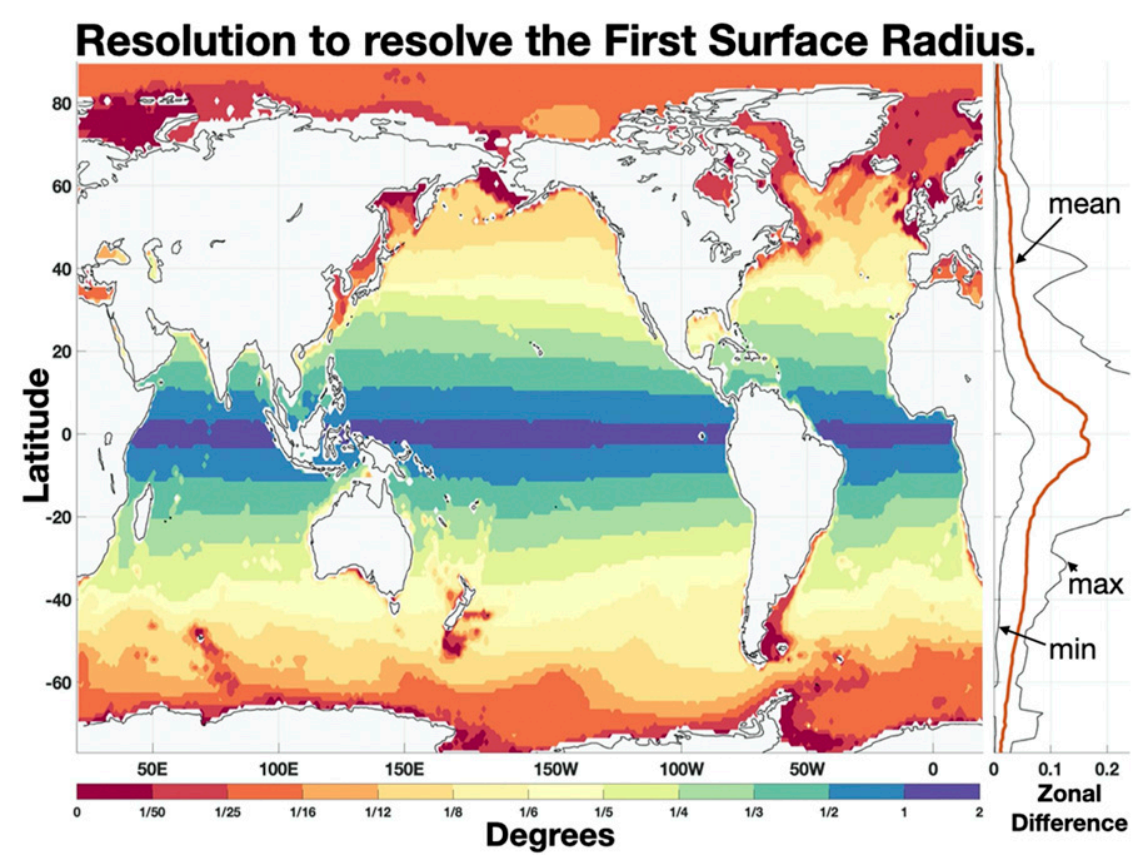

FIG. 10. The model (Mercator) resolution required to resolve the first surface radius. Inset: the zonally averaged difference from the resolution required for the flat bottom radius, with maximum and minimum values also indicated.

the flat bottom deformation radius, and more than would be expected from a shift to the surface radius. There are indications that this is due to an inverse energy cascade, i.e., due to eddy merging (Scott and Wang 2005; Chelton et al. 2011). However, such a cascade can occur among surface modes, and thus is not inconsistent with this basis (Early et al. 2011; LaCasce 2017).

The increase in the long surface mode phase speed is in line with the long wave speeds deduced from satellite measurements (Chelton and Schlax 1996). Diverse explanations were proposed previously for this, invoking mean flows (Killworth et al. 1997; Colin de Verdière and Tailleux 2005), uniform subsurface potential vorticity (Dewar 1998; de Szoeke and Chelton 1999), boundary effects (White 1977; LaCasce 2000), and wave instability (LaCasce and Pedlosky 2004; Isachsen et al. 2007). Others considered the effect of topography. Killworth and Blundell (1999) suggested topography could increase or decrease the phase speed but yielded a net zero effect over the whole Pacific. Later results (derived from WKB solutions and ray tracing) suggested topography had only a minor effect compared to that of a baroclinic mean flow (Killworth and Blundell 2003a,b, 2004, 2005). We note though that the vertical structures obtained in these papers differ significantly from the aforementioned current meter EOFs (Wunsch 1997; de La Lama et al. 2016).

On the other hand, Tailleux and McWilliams (2001) showed that having near-zero bottom velocities yields faster waves (albeit in the context of flat bottom modes). Aoki et al. (2009) and Hunt et al. (2012) examined the joint effect of the zero bottom flow condition and a mean flow (also with flat bottom modes), and found the bottom condition had a greater effect.
The resulting first mode vertical structure moreover closely resembles the first surface mode. The present results are in line with these papers, and confirm that the phase speed increase can be accounted for simply by altering the bottom boundary condition, i.e., without invoking coupled baroclinic modes. Such coupling is conceptually problematic, requiring phase locking between fast barotropic and slow baroclinic motions.

Interestingly, more recent analyses, based on tracking coherent vortices, yield westward speeds which are consistently slower than the flat bottom long wave speed, particularly at low latitudes (Chelton et al. 2011; Klocker and Marshall 2014). However, nonlinear vortices have different propagation characteristics, as they advect the ambient potential vorticity around them (Adem 1956; McWilliams and Flierl 1979; Reznik 1992; LaCasce 1998). The perturbed vorticity acts back on the vortices, causing them to drift both meridionally and zonally, as is also seen in satellite observations (Chelton et al. 2011; Klocker and Marshall 2014). As such, their zonal drift speed can differ from the long wave speed. Related to this, the question remains as to how the surface modes, obtained from the linear QG equations, pertain to fully nonlinear eddies.

The bathymetry in the present model is one dimensional (as in most of the aforementioned theoretical studies). This is a significant analytical simplification, but a ridge is an extreme form of topography since the flow cannot "go around" features. Samelson (1992) considered 2D topography in a twolayer model and found similar indications of deep flow suppression. Nevertheless this deserves further attention, and probably with continuous stratification. 
We have focused on the first surface mode, but the topographic mode is likely to be important as well, particularly where stratification is weak. The topographic mode can extend to the surface and has horizontal scales determined by the lateral structure of the topography. The mode deserves more attention than it has received previously, as it is likely important for dissipating mesoscale energy.

An interesting, though inconvenient, aspect is that the topographic mode is not orthogonal to the surface modes. Thus one cannot readily separate the modes in a current meter record, because knowing the topographic wave vertical scale requires knowing its horizontal scale, which is not possible with measurements at a single location. Further study is required to understand the partitioning between surface and topographic modes, perhaps using high resolution general circulation models.

The present results provide additional evidence that bathymetry has a significant impact on oceanic motion. Bathymetry makes the motion more surface trapped, affecting, for example, eddy mixing transport (Groeskamp et al. 2017, 2020). This sheds doubt on the usefulness of flat bottom models. The flat bottom was a conceptual simplification which greatly aided in theoretical development and this accounts for the widespread use of flat bottom baroclinic modes in interpreting observations and model data. But the evidence from current meter and satellite observations suggests that surface and topographic modes are probably more relevant for the ocean.

Acknowledgments. JHL was supported in part by the Norwegian Research Council project 302743 (The Rough Ocean). An early version of the article was submitted in 2019 to Geophysical Research Letters; on revising it for JPO, we learned that $\mathrm{C}$. Wortham was working on a similar problem, albeit with continuous stratification. His results complement those presented here.

\section{APPENDIX}

\section{WKB Solutions}

The numerical solutions to (14) were compared with WKB solutions, as done by Chelton et al. (1998). Those authors derived the WKB solution over a flat bottom using instead the modal structure for the vertical velocity $G(z)$ :

$$
\frac{d^{2}}{d z^{2}} G+\frac{N^{2}}{c^{2}} G=0
$$

where $N(z)$ is the buoyancy frequency and $c$ is the velocity associated with the mode. With a rigid upper surface at $z=0$ and a flat lower surface at $z=-H$, the boundary conditions are

$$
G=0 \quad \text { at } \quad z=0,-H .
$$

The WKB solution to (A1) to first order is

$$
G=A N^{-1 / 2} \cos \left(\frac{1}{c} \int_{-H}^{z} N d z\right)+B N^{-1 / 2} \sin \left(\frac{1}{c} \int_{-H}^{z} N d z\right)
$$

Satisfying the lower boundary condition requires $A=0$. Then the upper boundary condition yields

$$
\sin \left(\frac{1}{c} \int_{-H}^{0} N d z\right)=0
$$

or

$$
c=c_{n}=\frac{1}{n \pi} \int_{-H}^{0} N d z
$$

The first baroclinic mode has $n=1$ and a deformation radius:

$$
L_{d}=\frac{c_{1}}{|f|}=\frac{1}{\pi|f|} \int_{-H}^{0} N d z
$$

Also, the modal structure for the horizontal velocity is given by

$$
F(z)=A N^{1 / 2} \cos \left(\frac{1}{c} \int_{-H}^{z} N d z\right) .
$$

For the surface mode case, we use the modal equation for the horizontal velocity with Eq. (14), with boundary conditions

$$
F_{z}(0)=0, \quad F(-H)=0 .
$$

The WKB solution is

$$
F(z)=A N^{1 / 2} \cos \left(\frac{1}{c} \int_{-H}^{z} N d z\right)+B N^{1 / 2} \sin \left(\frac{1}{c} \int_{-H}^{z} N d z\right)
$$

Satisfying the lower boundary condition requires $A=0$. Substituting the sine portion of the solution into the upper boundary condition yields a transcendental equation:

$$
\frac{N_{z}(0)}{2 N(0)^{1 / 2}} \sin \left(\frac{1}{c} \int_{-H}^{z} N d z\right)+\frac{1}{c} N(0)^{3 / 2} \cos \left(\frac{1}{c} \int_{-H}^{z} N d z\right)=0,
$$

or

$$
\tan \left(\frac{1}{c} \int_{-H}^{z} N d z\right)=-\frac{2 N(0)^{2}}{c N_{z}(0)}
$$

This yields a discrete set of solutions for $c_{n}$. The first surface mode has $n=1$, with the first deformation radius given by $c_{1} /|f|$.

The surface mode solution is less convenient than that for the flat bottom as Eq. (A11) must be solved numerically. Moreover, the solution depends on the buoyancy frequency and its gradient at the surface, both of which are sensitive, for example, to the presence of a mixed layer. However, as the mixed layer generally has little impact on the modal structure, we neglected it and evaluated $N$ and $N_{z}$ at the mixed layer base.

\section{REFERENCES}

Adem, J., 1956: A series solution for the barotropic vorticity equation and its application in the study of atmospheric vortices. Tellus, 8, 364-372, https://doi.org/10.3402/tellusa.v8i3.9010.

Ajayi, A., J. Le Sommer, E. Chassignet, J. Molines, X. Xu, A. Albert, and E. Cosme, 2020: Spatial and temporal variability of the North Atlantic eddy field from two kilometric-resolution ocean 
models. J. Geophys. Res. Oceans, 125, e2019JC015827, https:// doi.org/10.1029/2019JC015827.

Anderson, D. L., and A. Gill, 1975: Spin-up of a stratified ocean, with applications to upwelling. Deep-Sea Res., 22, 583-596, https://doi.org/10.1016/0011-7471(75)90046-7.

Aoki, K., A. Kubokawa, H. Sasaki, and Y. Sasai, 2009: Midlatitude baroclinic Rossby waves in a high-resolution OGCM simulation. J. Phys. Oceanogr., 39, 2264-2279, https://doi.org/10.1175/ 2009JPO4137.1.

Bachman, S., and B. Fox-Kemper, 2013: Eddy parameterization challenge suite I: Eady spindown. Ocean Modell., 64, 12-28, https://doi.org/10.1016/j.ocemod.2012.12.003.

Barker, P. M., and T. J. McDougall, 2017: Stabilizing hydrographic profiles with minimal change to the water masses. J. Atmos. Oceanic Technol., 34, 1935-1945, https://doi.org/10.1175/ JTECH-D-16-0111.1.

- , and - 2020: Two interpolation methods using multiplyrotated Piecewise Cubic Hermite Interpolating Polynomials. J. Atmos. Oceanic Technol., 37, 605-619, https://doi.org/ 10.1175/JTECH-D-19-0211.1.

Benilov, E. S., 2001: Baroclinic instability of two-layer flows over one-dimensional bottom topography. J. Phys. Oceanogr., 31, 2019-2025, https://doi.org/10.1175/1520-0485(2001)031<2019: BIOTLF $>2.0 . \mathrm{CO} ; 2$.

Bobrovich, A., and G. Reznik, 1999: Planetary waves in a stratified ocean of variable depth. Part 2. Continuously stratified ocean. J. Fluid Mech., 388, 147-169, https://doi.org/10.1017/ S0022112099004863.

Charney, J., and G. R. Flierl, 1981: Oceanic analogues of large-scale atmospheric motions. Evolution of Physical Oceanography, C. Wunsch and B. Warren, Eds., MIT Press, 266-290.

Chassignet, E., and X. Xu, 2017: Impact of horizontal resolution $\left(1 / 12^{\circ}\right.$ to $\left.1 / 50^{\circ}\right)$ on Gulf Stream separation, penetration, and variability. J. Phys. Oceanogr., 47, 1999-2021, https://doi.org/ 10.1175/JPO-D-17-0031.1.

Chelton, D., and M. Schlax, 1996: Global observations of oceanic Rossby waves. Science, 272, 234-238, https://doi.org/10.1126/ science.272.5259.234.

_ R. Deszoeke, M. Schlax, K. El Naggar, and N. Siwertz, 1998: Geographical variability of the first baroclinic Rossby radius of deformation. J. Phys. Oceanogr., 28, 433-460, https://doi.org/ 10.1175/1520-0485(1998)028<0433:GVOTFB > 2.0.CO;2.

—, M. Schlax, R. Samelson, and R. de Szoeke, 2007: Global observations of large oceanic eddies. Geophys. Res. Lett., 34, L15606, https://doi.org/10.1029/2007GL030812.

,$- \ldots$, and R. M. Samelson, 2011: Global observations of nonlinear mesoscale eddies. Prog. Oceanogr., 91, 167-216, https://doi.org/10.1016/j.pocean.2011.01.002.

Colin de Verdière, A., and R. Tailleux, 2005: The interaction of a baroclinic mean flow with long Rossby waves. J. Phys. Oceanogr., 35, 865-879, https://doi.org/10.1175/JPO2712.1.

de La Lama, M. S., J. H. LaCasce, and H. Fuhr, 2016: The vertical structure of ocean eddies. Dyn. Stat. Climate Syst., 1, dzw001, https://doi.org/10.1093/climsys/dzw001.

de Szoeke, R., and D. Chelton, 1999: The modification of long planetary waves by homogeneous potential vorticity layers. J. Phys. Oceanogr., 29, 500-511, https://doi.org/10.1175/15200485(1999)029<0500:TMOLPW>2.0.CO;2.

Dewar, W., 1998: On "too fast" baroclinic planetary waves in the general circulation. J. Phys. Oceanogr., 28, 1739-1758, https:// doi.org/10.1175/1520-0485(1998)028<1739:OTFBPW>2.0.CO;2.

Dong, B. W., and R. T. Sutton, 2002: Adjustment of the coupled oceanatmosphere system to a sudden change in the Thermohaline
Circulation. Geophys. Res. Lett., 29, 1728, https://doi.org/ 10.1029/2002GL015229.

Early, J., R. Samelson, and D. Chelton, 2011: The evolution and propagation of quasigeostrophic ocean eddies. J. Phys. Oceanogr., 41, 1535-1555, https://doi.org/10.1175/ 2011JPO4601.1.

Gent, P., and J. McWilliams, 1990: Isopycnal mixing in ocean circulation models. J. Phys. Oceanogr., 20, 150-155, https://doi.org/ 10.1175/1520-0485(1990)020<0150:IMIOCM > 2.0.CO;2.

Gill, A. E., 1982: Atmosphere-Ocean Dynamics. Academic Press, $662 \mathrm{pp}$.

Goff, J., 2010: Global prediction of abyssal hill root-meansquare heights from small-scale altimetric gravity variability. J. Geophys. Res. Solid Earth, 115, B12104, https:// doi.org/10.1029/2010JB007867.

Griffies, S. M., 1998: The Gent-McWilliams skew flux. J. Phys. Oceanogr., 28, 831-841, https://doi.org/10.1175/1520-0485(1998) 028<0831:TGMSF $>2.0 . \mathrm{CO} ; 2$.

Groeskamp, S., B. M. Sloyan, J. D. Zika, and T. J. McDougall, 2017: Mixing inferred from an ocean climatology and surface fluxes. J. Phys. Oceanogr., 47, 667-687, https://doi.org/10.1175/ JPO-D-16-0125.1.

— , J. H. LaCasce, T. J. McDougall, and M. Foré, 2020: Fulldepth global estimates of ocean mesoscale eddy mixing from observations and theory. Geophys. Res. Lett., in press.

Hallberg, R., 2013: Using a resolution function to regulate parameterizations of oceanic mesoscale eddy effects. Ocean Modell., 72, 92-103, https://doi.org/10.1016/j.ocemod.2013.08.007.

Huang, R. X., M. A. Cane, N. Naik, and P. Goodman, 2000: Global adjustment of the thermocline in response to deepwater formation. Geophys. Res. Lett., 27, 759-762, https://doi.org/ 10.1029/1999GL002365.

Hunt, F., R. Tailleux, and J. Hirschi, 2012: The vertical structure of oceanic Rossby waves: A comparison of high-resolution model data to theoretical vertical structures. Ocean Sci., 8, 1935, https://doi.org/10.5194/os-8-19-2012.

Isachsen, P., J. LaCasce, and J. Pedlosky, 2007: Rossby wave instability and apparent phase speeds in large ocean basins. J. Phys. Oceanogr., 37, 1177-1191, https://doi.org/10.1175/JPO3054.1.

Jackett, D. R., and T. J. McDougall, 1997: A neutral density variable for the world's oceans. J. Phys. Oceanogr., 27, 237-263, https://doi.org/10.1175/1520-0485(1997)027<0237:ANDVFT> 2.0.CO;2.

Killworth, P. D., and J. Blundell, 1999: The effect of bottom topography on the speed of long extratropical planetary waves. J. Phys. Oceanogr., 29, 2689-2710, https://doi.org/10.1175/ 1520-0485(1999)029<2689:TEOBTO >2.0.CO;2.

$\longrightarrow$, and,$- 2003 \mathrm{a}$ : Long extratropical planetary wave propagation in the presence of slowly varying mean flow and bottom topography. Part I: The local problem. J. Phys. Oceanogr., 33, 784-801, https://doi.org/10.1175/1520-0485(2003)33<784: LEPWPI $>2.0 . \mathrm{CO} ; 2$.

$\longrightarrow$, and - 2003b: Long extratropical planetary wave propagation in the presence of slowly varying mean flow and bottom topography. Part II: Ray propagation and comparison with observations. J. Phys. Oceanogr., 33, 802-821, https://doi.org/ 10.1175/1520-0485(2003)33<802:LEPWPI > 2.0.CO;2.

$\longrightarrow$, and - 2004: The dispersion relation for planetary waves in the presence of mean flow and topography. Part I: Analytical theory and one-dimensional examples. J. Phys. Oceanogr., 34, 2692-2711, https://doi.org/10.1175/JPO2635.1.

—, and _ , 2005: The dispersion relation for planetary waves in the presence of mean flow and topography. Part II: 
Two-dimensional examples and global results. J. Phys. Oceanogr., 35, 2110-2133, https://doi.org/10.1175/JPO2817.1.

—, D. B. Chelton, and R. A. de Szoeke, 1997: The speed of observed and theoretical long extratropical planetary waves. J. Phys. Oceanogr., 27, 1946-1966, https://doi.org/10.1175/ 1520-0485(1997)027<1946:TSOOAT>2.0.CO;2.

Kirtman, B. P. C., F. Bitz, W. Bryan, J. Collins, and N. Dennis, 2012: Impact of ocean model resolution on CCSM climate simulations. Climate Dyn., 39, 1303-1328, https://doi.org/ 10.1007/s00382-012-1500-3.

Klocker, A., and D. Marshall, 2014: Advection of baroclinic eddies by depth mean flow. Geophys. Res. Lett., 41, 3517-3521, https://doi.org/10.1002/2014GL060001.

LaCasce, J. H., 1998: A geostrophic vortex on a slope. J. Phys. Oceanogr., 28, 2362-2381, https://doi.org/10.1175/15200485(1998)028<2362:AGVOAS > 2.0.CO;2.

—_, 2000: Geostrophic turbulence over a slope. J. Phys. Oceanogr., 30, 1305-1324, https://doi.org/10.1175/15200485(2000)030<1305:GTOAS > 2.0.CO;2.

- 2017: The prevalence of oceanic surface modes. Geophys. Res. Lett., 44, 11 097-11 105, https://doi.org/10.1002/2017GL075430.

— and the oceanic eddy field. J. Phys. Oceanogr., 34, 2027-2041, https://doi.org/10.1175/1520-0485(2004)034<2027:TIORBM> 2.0.CO;2.

—_ J. Escartin, E. Chassignet, and X. Xu, 2019: Jet instability over smooth, corrugated and realistic bathymetry. J. Phys. Oceanogr., 49, 585-605, https://doi.org/10.1175/JPO-D-180129.1.

McCreary, J., Jr., 1983: A model of tropical ocean-atmosphere interaction. Mon. Wea. Rev., 111, 370-387, https://doi.org/ 10.1175/1520-0493(1983)111<0370:AMOTOA > 2.0.CO;2.

McDougall, T. J., 2003: Potential enthalpy: A conservative oceanic variable for evaluating heat content and heat fluxes. J. Phys. Oceanogr., 33, 945-963, https://doi.org/10.1175/15200485(2003)033<0945:PEACOV > 2.0.CO;2.

— locity. Part II: Isopycnal interpretation and the tracer and momentum equations. J. Phys. Oceanogr., 31, 1222-1246, https://doi.org/10.1175/1520-0485(2001)031<1222:TTRMVP> 2.0.CO;2.

—- and P. M. Barker, 2011: Getting started with TEOS-10 and the Gibbs Seawater (GSW) Oceanographic Toolbox. SCOR/IAPSO WG127, 28 pp., http://www.teos-10.org/pubs/ Getting_Started.pdf.

—, D. R. Jackett, F. J. Millero, R. Pawlowicz, and P. M. Barker, 2012: A global algorithm for estimating absolute salinity. Ocean Sci., 8, 1123-1134, https://doi.org/10.5194/os-8-11232012.

McWilliams, J., and G. Flierl, 1979: On the evolution of isolated, nonlinear vortices. J. Phys. Oceanogr., 9, 1155-1182, https:// doi.org/10.1175/1520-0485(1979)009<1155:OTEOIN > 2.0.CO;2.

Moreton, S., D. Ferreira, M. Roberts, and H. Hewitt, 2020: Evaluating surface eddy properties in coupled climate simulations with 'eddy-present' and 'eddy-rich' ocean resolution. Ocean Modell., 147, 101567, https://doi.org/10.1016/ j.ocemod.2020.101567.

Osychny, V., and P. Cornillon, 2004: Properties of Rossby waves in the North Atlantic estimated from satellite data. J. Phys.
Oceanogr., 34, 61-76, https://doi.org/10.1175/1520-0485(2004) 034<0061:PORWIT>2.0.CO;2.

Pedlosky, J., 1987: Geophysical Fluid Dynamics. 2nd ed. SpringerVerlag, 710 pp.

Reznik, G., 1992: Dynamics of singular vortices on a betaplane. J. Fluid Mech., 240, 405-432, https://doi.org/10.1017/ S0022112092000144.

_ of variable depth. Part 1. Two-layer model. J. Fluid Mech., 388, 115-145, https://doi.org/10.1017/S0022112099004875.

Rhines, P., 1970: Edge-, bottom-, and Rossby waves in a rotating stratified fluid. Geophys. Astrophys. Fluid Dyn., 1, 273-302, https://doi.org/10.1080/03091927009365776.

Rocha, C. B., T. K. Chereskin, S. T. Gille, and D. Menemenlis, 2016: Mesoscale to submesoscale wavenumber spectra in Drake Passage. J. Phys. Oceanogr., 46, 601-620, https:// doi.org/10.1175/JPO-D-15-0087.1.

Samelson, R. M., 1992: Surface-intensified Rossby waves over rough topography. J. Mar. Res., 50, 367-384, https://doi.org/ 10.1357/002224092784797593.

Scott, R., and F. Wang, 2005: Direct evidence of an oceanic inverse kinetic energy cascade from satellite altimetry. J. Phys. Oceanogr., 35, 1650-1666, https://doi.org/10.1175/JPO2771.1.

Stammer, D., 1997: Global characteristics of ocean variability estimated from regional TOPEX/POSEIDON altimeter measurements. J. Phys. Oceanogr., 27, 1743-1769, https://doi.org/ 10.1175/1520-0485(1997)027<1743:GCOOVE >2.0.CO;2.

Tailleux, R., and J. C. McWilliams, 2000: Acceleration, creation, and depletion of wind-driven, baroclinic Rossby waves over an ocean ridge. J. Phys. Oceanogr., 30, 2186-2213, https://doi.org/ 10.1175/1520-0485(2000)030<2186:ACADOW>2.0.CO;2.

$\longrightarrow$, and - 2001: The effect of bottom pressure decoupling on the speed of extratropical, baroclinic Rossby waves. J. Phys. Oceanogr., 31, 1461-1476, https://doi.org/10.1175/ 1520-0485(2001)031<1461:TEOBPD>2.0.CO;2.

Trefethen, L. N., 2001: Spectral Methods in MATLAB. SIAM, $184 \mathrm{pp}$.

Vanneste, J., 2001: Mode conversion for Rossby waves over topography: Comments on "localized coupling between surface- and bottom-intensified flow over topography. J. Phys. Oceanogr., 31, 1922-1925, https://doi.org/10.1175/ 1520-0485(2001)031<1922:MCFRWO>2.0.CO;2.

_ 2003: Nonlinear dynamics over rough topography: Homogeneous and stratified quasi-geostrophic theory. J. Fluid Mech., 474, 299-318, https://doi.org/10.1017/S0022112002002707.

White, W. B., 1977: Annual forcing of baroclinic long waves in the tropical North Pacific Ocean. J. Phys. Oceanogr., 7, 50-61, https://doi.org/10.1175/1520-0485(1977)007<0050:AFOBLW> 2.0.CO;2.

Wortham, C., and C. Wunsch, 2014: A multidimensional spectral description of ocean variability. J. Phys. Oceanogr., 44, 944966, https://doi.org/10.1175/JPO-D-13-0113.1.

Wunsch, C., 1997: The vertical partition of oceanic horizontal kinetic energy. J. Phys. Oceanogr., 27, 1770-1794, https://doi.org/ 10.1175/1520-0485(1997)027<1770:TVPOOH>2.0.CO;2. , 2015: Modern Observational Physical Oceanography: Understanding the Global Ocean. Princeton University Press, 493 pp. 
Copyright of Journal of Physical Oceanography is the property of American Meteorological Society and its content may not be copied or emailed to multiple sites or posted to a listserv without the copyright holder's express written permission. However, users may print, download, or email articles for individual use. 